GLACIAL EROSION

\section{Making and breaking mountains}

Glaciers are erosional forces that influence mountain height and relief, and are impacted by climate and tectonics. In some mountain ranges, it has been proposed that glaciers control mountain topography by eroding high elevations at and above the snowline - referred to as the glacial buzzsaw. In others, glaciers are suggested to protect mountain tops from erosion. Two new studies in Earth and Planetary Science Letters offer new insight into the role of glaciers in eroding mountains.

Günther Prasicek at the University of Lausanne, Switzerland, and

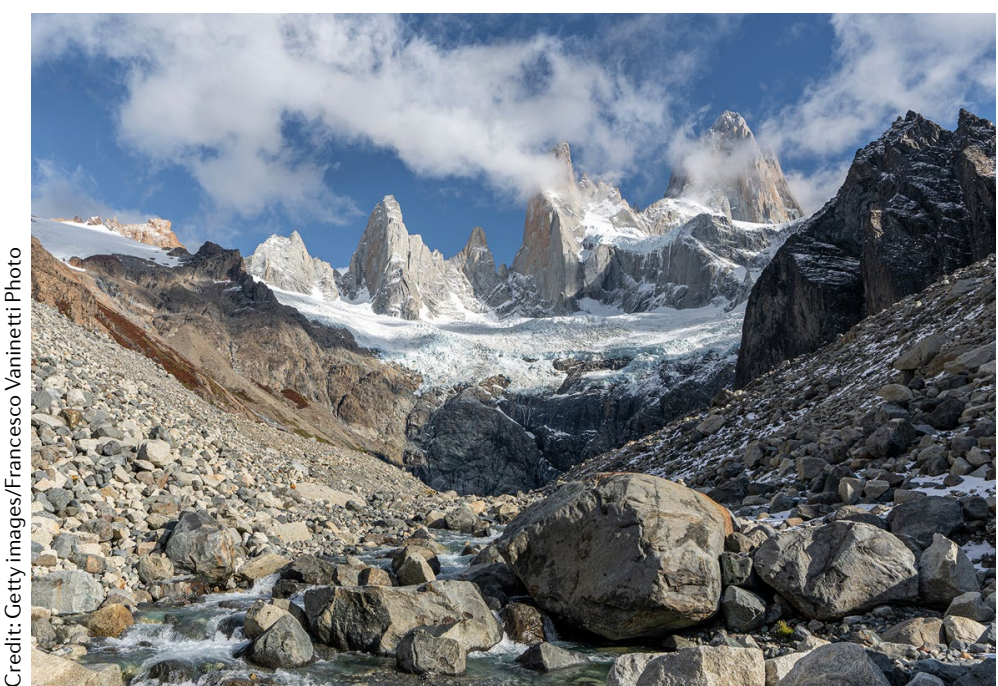

Jingtao Lai and Alison Anders of the University of Illinois at UrbanaChampaign, IL, USA, honed into how geothermal heat from the underlying mountain bedrock impacts glacial ice dynamics and subsequently glacial erosion. Coupling glacial erosion and ice sheet models over different tectonic regimes, which have different geothermal heat fluxes, demonstrated that increased heat flux causes faster erosion rates and at higher elevations. Thus, glaciers in tectonically active mountain belts (which have high geothermal heat fluxes) can cause the glacial buzzsaw effect, whereas areas with lower heat fluxes experience slower and lower erosion.

The impact of glaciers on mountain erosion and topography, and its links to tectonic regimes and climatic changes are difficult to observe as they occur over geological timescales. These two modelling-based approaches bring new quantitative insight into the balance between these various forces. Refining these models, for example by including more detailed hydrology and increasing the collection and incorporation of empirical data, will further improve our understanding of the long-term role of glaciers in mountain building.

Laura Zinke

ORIGINAL ARTICLES Prasicek et al. A glacial buzzsaw effect generated by efficient erosion of temperate glaciers in a steady state model. Earth Planet. Sci. Lett. https://doi.org/10.1016/ j.epsl.2020.116350|Lai, J. \& Anders, A. M. Tectonic controls on rates and spatial patterns of glacial erosion through geothermal heat flux. Earth Planet. Sci. Lett. https://doi.org/10.1016/j.eps..2020.116348 